\title{
A RETROSPECTIVE OBSERVATIONAL STUDY ON PATIENTS INTOXICATED BY DRUGS AND OTHER XENOBIOTICS
}

\section{EWA SAWICKA ${ }^{1}$, PAULINA KARTUSZYŃSKA ${ }^{2}$, HALINA KUCZYŃSKA ${ }^{2}$, and AGNIESZKA PIWOWAR ${ }^{1}$}

\author{
Wroclaw Medical University, Wrocław, Poland \\ ${ }^{1}$ Faculty of Pharmacy with Division of Laboratory Diagnostics, Department of Toxicology \\ ${ }^{2}$ Students Science Club of Department of Toxicology
}

\begin{abstract}
Objectives: Many research studies conducted in various toxicology centers point to drugs as the most common cause of intoxication. Long-term observations make it possible to clarify the nature of these poisonings. The aim of this study was to examine the trends and reasons of intoxication in patients hospitalized over a 10-year observation period (2005-2015), as well as to compare the number of patients poisoned with nonsteroidal anti-inflammatory drugs (NSAIDs), mainly over-the-counter (OTC) drugs. Material and Methods: A retrospective observational study examined the medical documentation of patients hospitalized in the Department of Toxicology and Internal Diseases of the T. Marciniak Lower Silesian Specialist Hospital in Wrocław in 2005-2015, including the analysis of the causes of intoxication as well as total poisoning-related death statistics. Quarterly and annual analyses of the numerical data, and comparisons of the frequency of poisonings were included. The patient population from the area of Lower Silesia, Poland, was examined. Results: The number of hospitalized patients has increased, with attempted suicide being the leading cause of death. Male intoxication and mortality have been found to predominate. Drugs are the most common cause of poisoning, and among these the most common are sedatives and psychotropic drugs. Intoxication due to NSAIDs, especially OTC drugs, increased significantly in the observation period. In 2005 no fatal cases were reported as a result of NSAID intoxication, while in 2015 mortality significantly increased to $43 \%$. Conclusions: The lack of a common trend in poisonings is observed but the number of hospitalized patients has increased, especially among young people, which is consistent with global trends. Drugs are the most common cause of mortality, and a significant increase in NSAID (mainly OTC) poisonings in particular indicates the growing prevalence of an uncontrolled use of these drugs. Int J Occup Med Environ Health. 2019;32(4):489-501
\end{abstract}

Key words:

alcohol, drugs, carbon monoxide, pesticides, intoxication, retrospective observation

\section{INTRODUCTION}

Acute poisonings represent a significant global public health problem. Their epidemiology, taking into account whether the poisoning came about for accidental or intentional causes, varies among countries and changes over time [1-3]. Drugs are indicated as the most common cause of intoxication, with a higher incidence than pesticides, mushrooms or carbon monoxide. Alcohol poisonings constitute a separate group; however, these statistics are often incomplete due to the large number of mixed alcohol-drug poisonings [4].

Many patients are hospitalized every year due to deliberate or accidental intoxication, and mostly due to polypharmacotherapy [5]. The nature of poisonings depends on the individual's level of tolerance, sensitivity, metabolism and many other factors, among which age is often significantly connected with different types of intoxication. It is indicated that young people are more likely to be victims of

Received: April 4, 2018. Accepted: March 15, 2019.

Corresponding author: Ewa Sawicka, Wroclaw Medical University, Faculty of Pharmacy with Division of Laboratory Diagnostics, Department of Toxicology, Borowska 211, 50-556 Wrocław, Poland (e-mail: ewa.sawicka@umed.wroc.pl). 
targeted poisoning, while in older people intoxication is often connected with using too many different drugs, and adverse drug reactions (ADR) [6,7].

Statistical analysis of the population of Norway indicates drugs, mainly benzodiazepines, as the most common cause of intoxication, with ethanol in the second place. The most serious effects of poisoning were reported after overdoses of both alcohol and drugs [8]. In recent years both the selection and availability of over-the-counter (OTC) drugs have expanded considerably. Moreover, the sale of these drugs outside pharmacies is significantly more frequent, leading to a growth in intoxication rates due to these drugs. Poland is one of the countries where the number of drugs sold outside pharmacies is very large [9]. Poisonings are the third leading cause of death in Poland (6\%), after cardiovascular diseases and cancer [1].

The aim of this study was to investigate trends in the causes of intoxication (drugs, alcohols, pesticides, carbon monoxide or fungal poisoning) in patients from the area of Lower Silesia admitted to hospital over a 10-year observation period (2005-2015). The authors' ultimate goal was to compare the number of patients poisoned with nonsteroidal anti-inflammatory drugs (NSAIDs) and analgesic drug poisoning (mainly OTC drugs), in 2005 and again 10 years later (2015). Ethical approval was not required for this study in accordance with Polish regulations [10].

\section{MATERIAL AND METHODS}

This retrospective observational study examined quarterly and annual clinical data on patients admitted to the Department of Internal Medicine and Toxicology in the Lower Silesian Specialist Hospital in 2005-2015. Causes of poisoning, as well as total death statistics, were analyzed and evaluated. The total number of hospitalized patients amounted to 12215 . Causes of intoxication were analyzed by gender, age and mortality rate. The patients were poisoned by the following agents: alcohols, pesticides, carbon monoxide and mushrooms, but primarily medicines, including OTC drugs. Three age groups were differentiated, i.e., 15-30, > 30-50 and $>50$ years old. Both the numerical data and the frequency of poisonings were compared and summarized.

\section{RESULTS}

The number of patients (both men and women) hospitalized due to intoxication during the analyzed period is shown in Figure 1a, while the total mortality rate is shown in Figure 1b. The total number of patients hospitalized over the 10-year period increased from 941 in 2005 to 1164 in 2015, and 168 of the hospitalized patients died (1.37\%). Among the hospitalized patients, males were dominant, and the mortality rate was also higher among men. In this group, an increasing tenden-
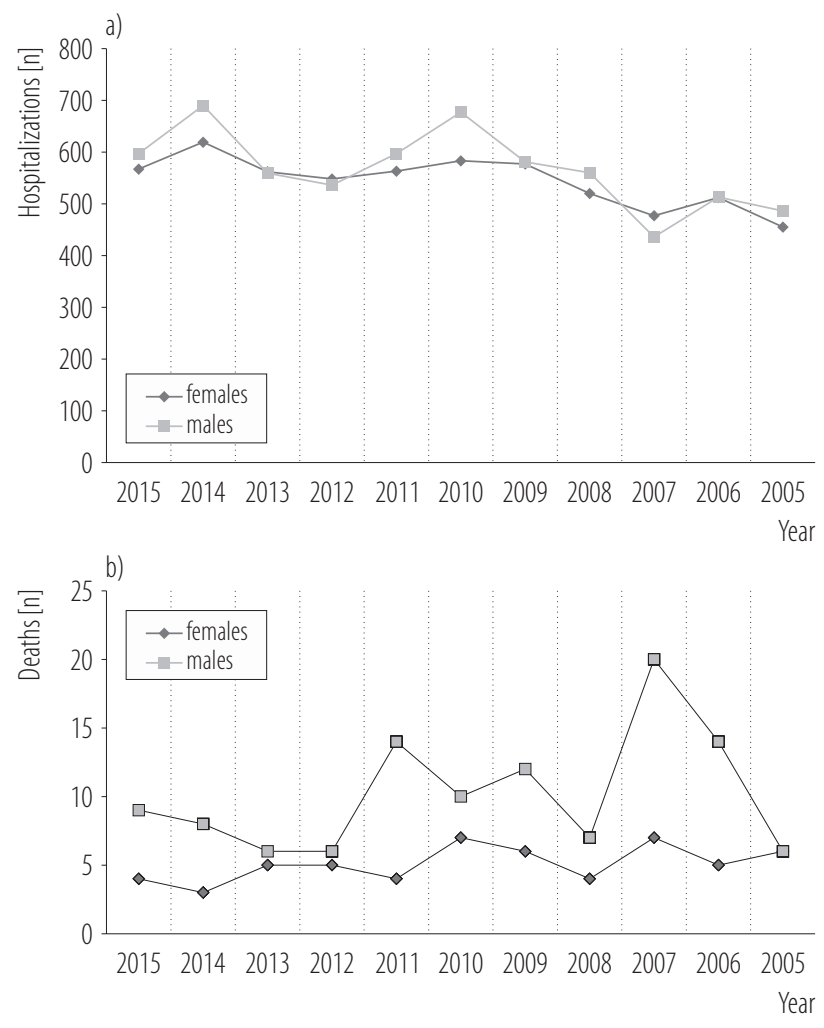

Figure 1. a) Hospitalizations and b) deaths due to intoxication over the years of observation, among the patients hospitalized in the Department of Toxicology and Internal Diseases of the T. Marciniak Lower Silesian Specialist Hospital in Wrocław, Poland, in 2005-2015 

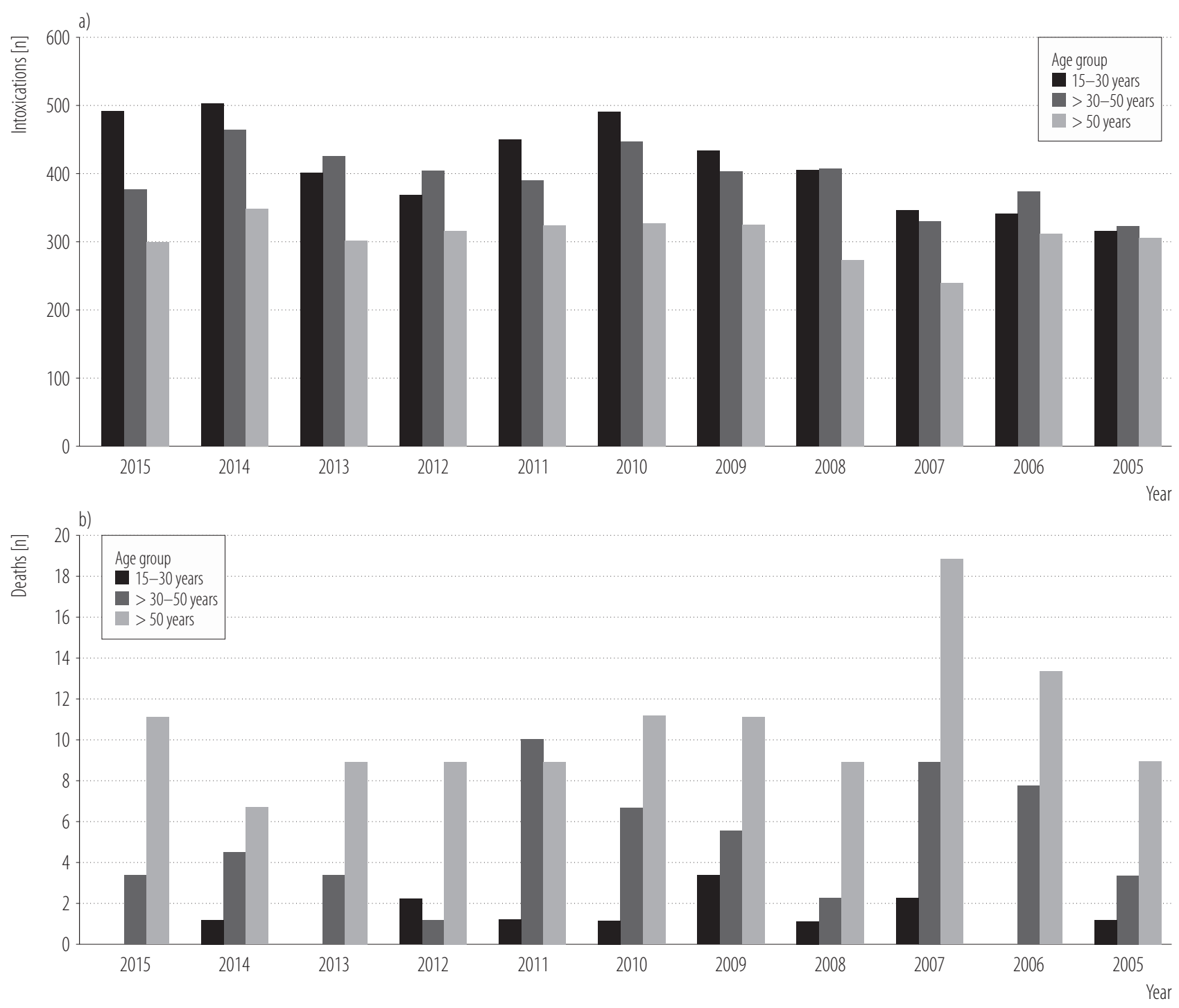

Figure 2. a) Intoxications and b) deaths among the patients hospitalized in the Department of Toxicology and Internal Diseases of the T. Marciniak Lower Silesian Specialist Hospital in Wrocław, Poland, in 2005-2015, by age group

cy was revealed, especially at the start of the observations, when the highest number of male deaths was noted (2007), being about $125 \%$ higher than in 2005. Among women, the mortality rate slightly decreased during the period of study, while this trend was not observed among men (Figures 1a and 1b).

The number of patients hospitalized due to intoxication, and the mortality rates presented by age group, are shown in Figures $2 \mathrm{a}$ and $2 \mathrm{~b}$, respectively. There is no uniform trend in the number of intoxications among the age groups, but some tendencies were revealed. At the beginning of the observations, the number of intoxicated patients in all the age groups was relatively similar but, at the end, intoxication was more likely to occur among younger people. However, the oldest patients ( $>50$ years) constituted the smallest group (25.4\%) in each of the analyzed years.

Moreover, intoxication was most likely to occur among young people, aged 15-30 (37.1\%). From 2009-2015, the 


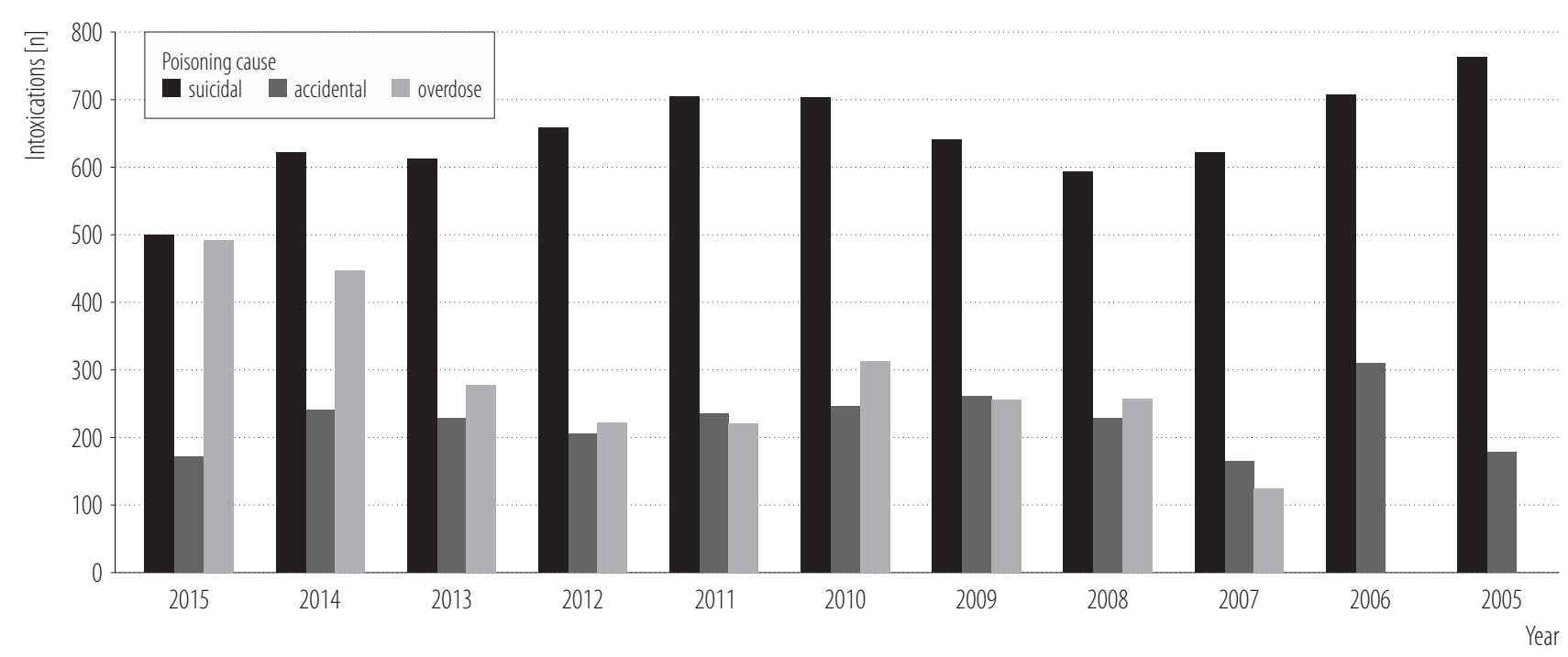

Figure 3. The causes of poisoning among the patients hospitalized in the Department of Toxicology and Internal Diseases of the T. Marciniak Lower Silesian Specialist Hospital in Wrocław, Poland, in 2005-2015

number of intoxicated young people (15-30 years old) significantly increased (by about $25 \%$ ), compared to the initial time of observation. Whereas the highest mortality was evident among elder patients, the rate of mortality among young patients was at a similar low level during the observations. Significantly, there were no cases of death in this group during the final year of observation (Figures $2 \mathrm{a}$ and $2 b$ ).

The authors distinguished 3 main groups of poisonings: suicidal, accidental and overdose (Figure 3). Suicide attempts formed the largest group (58\%), prevailing in the observations from almost all the years. Accidental poisonings accounted for $20 \%$, and overdose poisonings for $22 \%$. Moreover, in the last 2 years of the study, 2014 and 2015, a significant increase in overdose poisonings was noted. In the initial years of the study (2005 and 2006), no patient was admitted to hospital for this reason (Figure 3). Distribution of the causes of poisoning during the observation period is shown in Figure 4.

Drugs currently cause the majority of poisonings (about 60\%). The authors determined that in 2005 they accounted for $76 \%$ of all the patients hospitalized for poisoning, while in 2015 the proportion was 49\%. Alcohol intoxication was in the second place (1799 cases), while gas poisoning was the third reason for admission to hospital (1314 cases). Narcotics and hallucinogenic substances formed the fourth cause of intoxication (about 7.5\%), (Figure 4). Moreover, the authors noted that single drugs were the causes of intoxication in $74 \%$ of the cases reported over the years 2005-2015, but mixed drugs were the causes of $26 \%$ of poisonings. However, the authors also observed some changes regarding the reasons of patients' death in the reference period: in $67 \%$ of the cases, death was induced by single drugs while in $33 \%$ by mixed drugs.

Among all the drugs indicated as the causes of intoxication, the most common ones belonged to the group of sedatives, hypnotics and antiepileptics, but also psychotropic drugs (Figure 5). The comparisons of the shares of various drug groups in poisonings and deaths in the years 2005 and 2015 are presented in Figures 6a, 6b, 6c and 6d, respectively. In the period of observation, the first group of drugs became less popular, while psychotropic drugs slowly gained popularity, on a year-by-year basis. 


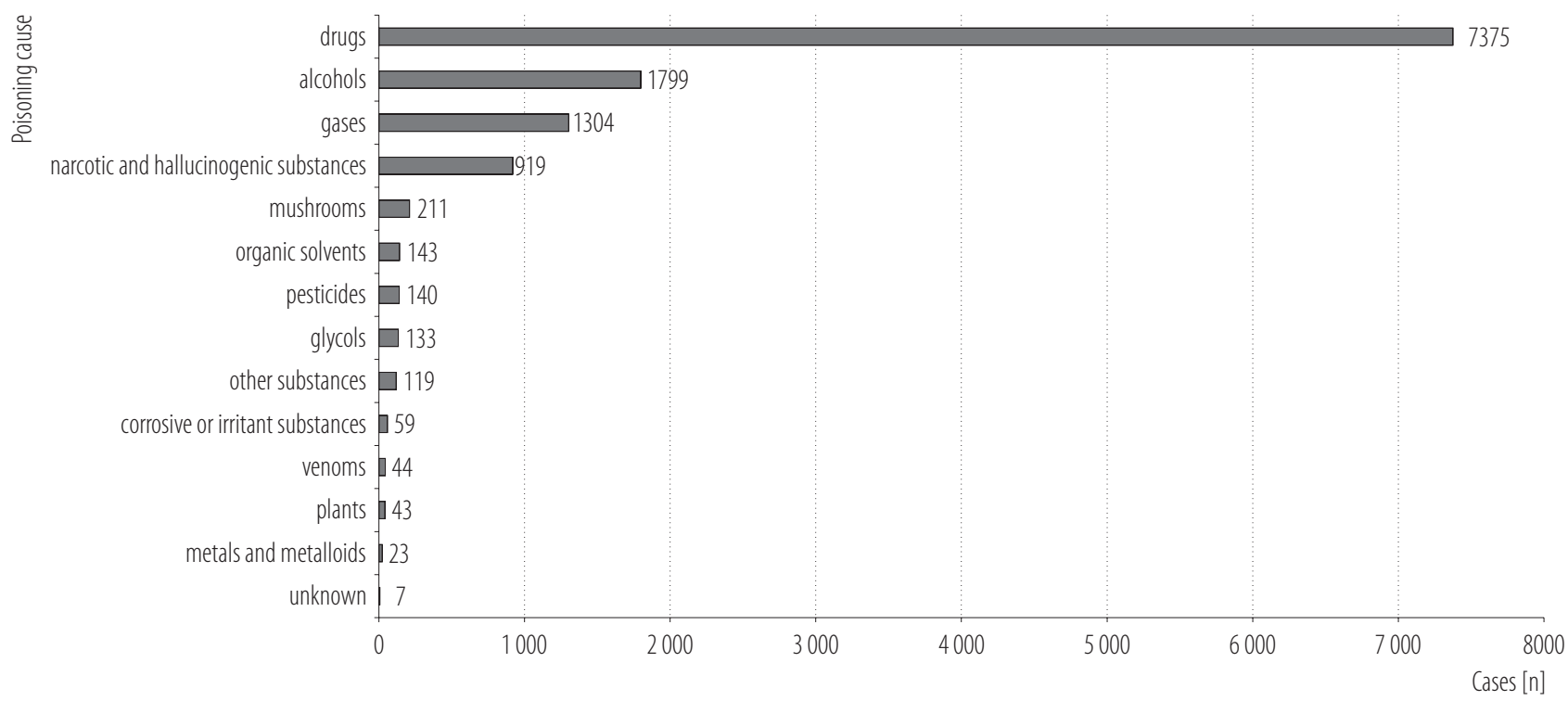

Figure 4. The most common causes of poisoning among the patients admitted to the Department of Toxicology and Internal Diseases of the T. Marciniak Lower Silesian Specialist Hospital in Wrocław, Poland, in 2005-2015

The number of intoxications caused by NSAIDs and analgesic drugs, such as paracetamol, ibuprofen and acetylsalicylic acid (usually OTC), has increased significantly over the last few years (Figures $6 a$ and $6 b$ ). In 2005 no fatal cases were reported as a result of intoxication caused by NSAIDs or analgesic drugs, while in 2015 they already accounted for $43 \%$ of fatal cases (Figures $6 \mathrm{c}$ and $6 \mathrm{~d}$ ). Moreover, it is worth noting that sedatives, antiepileptics and hypnotic drugs are becoming less significant causes of poisoning (56\% in 2005 and $37 \%$ in 2015) (Figures 6a and 6b), and the cases of death caused by these drugs dropped rapidly from $40 \%$ in 2005 to $14 \%$ in 2015 (Figures 6c and 6d). Interestingly, the rates of intoxication caused by

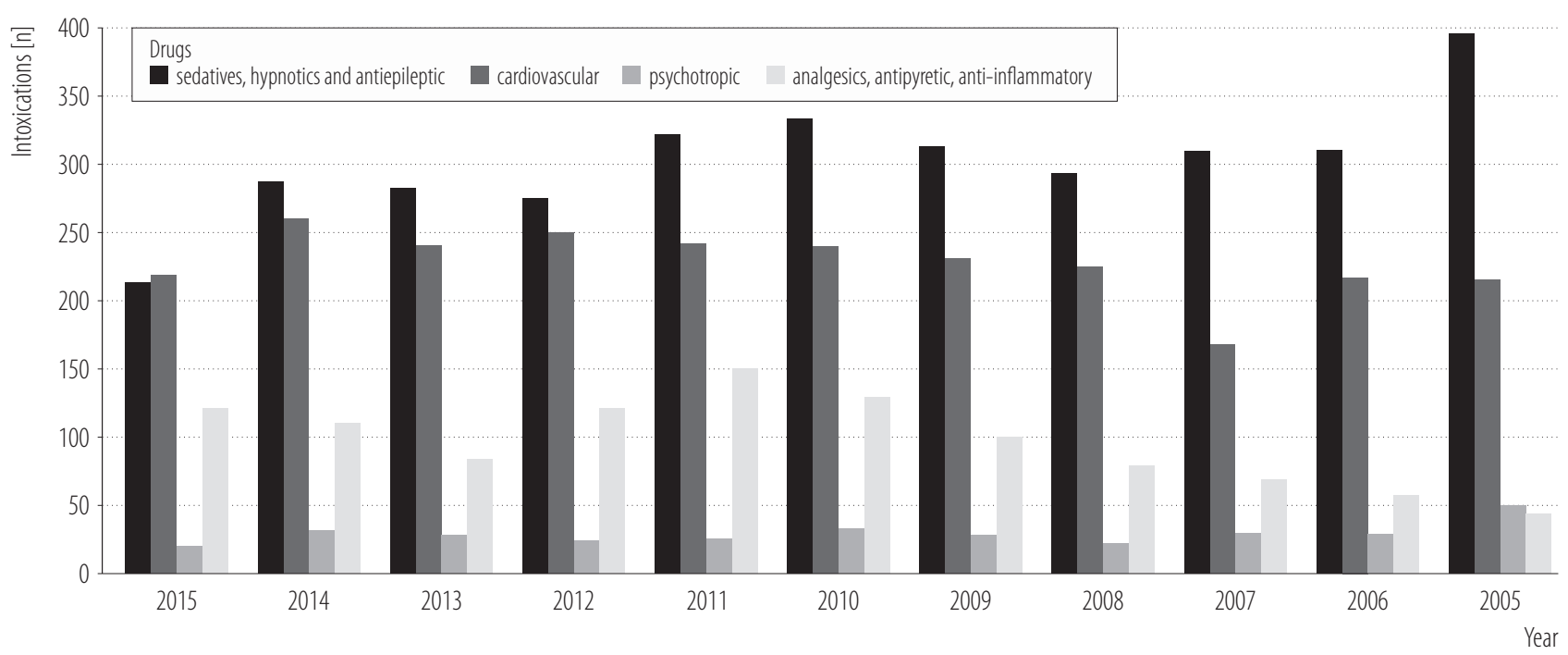

Figure 5. The groups of drugs indicated as the causes of intoxication among the patients hospitalized in the Department of Toxicology and Internal Diseases of the T. Marciniak Lower Silesian Specialist Hospital in Wrocław, Poland, in 2005-2015 

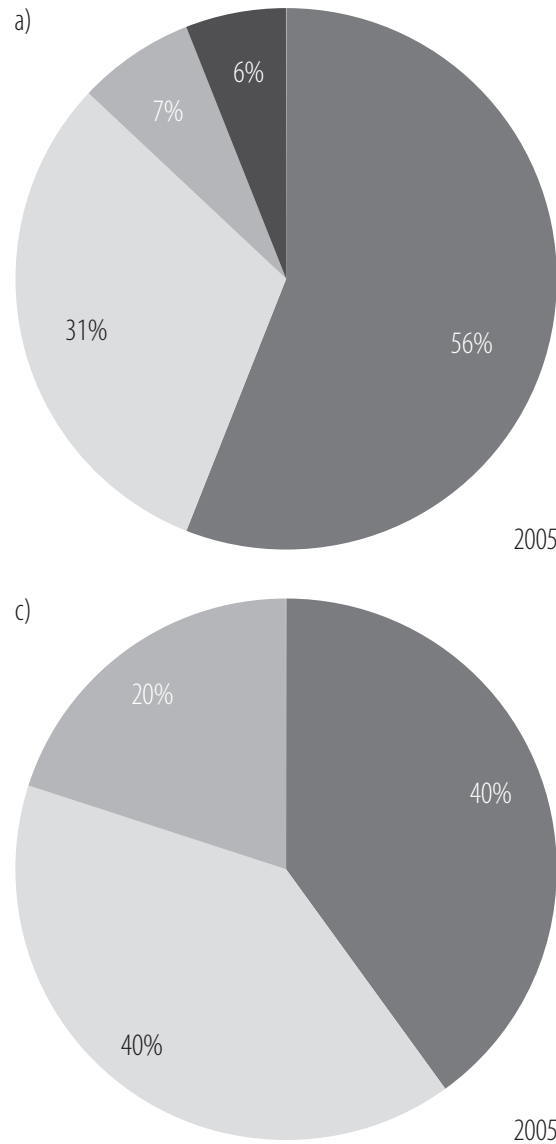

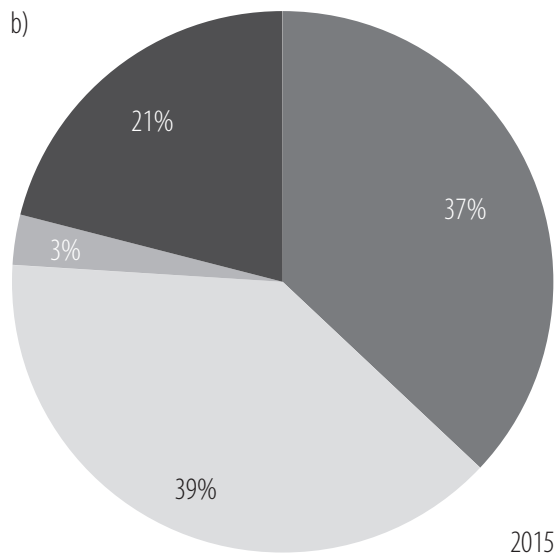

d)

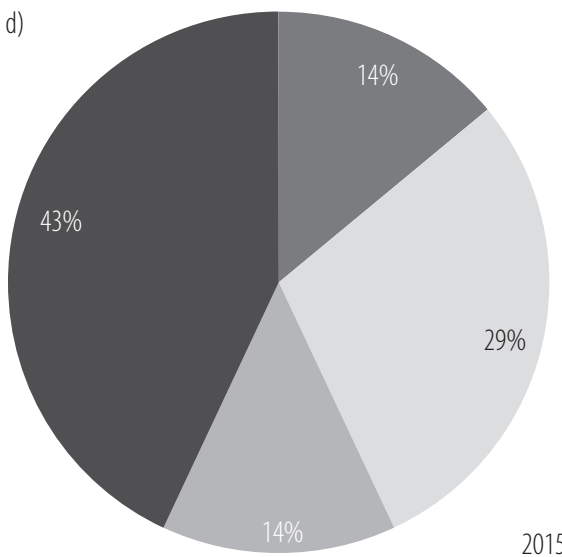

$$
\begin{aligned}
& \text { Drugs } \\
& \square \text { sedatives, hypnotics and antiepileptic } \square \text { psychotropic } \square \text { cardiovascular } \square \text { analgesics, antipyretic, anti-inflammatory }
\end{aligned}
$$

Figure 6. The comparison of drug groups in terms of poisonings in a) 2005 and b) 2015, and in terms of deaths in c) 2005 and d) 2015, among the patients hospitalized in the Department of Toxicology and Internal Diseases of the T. Marciniak Lower Silesian Specialist Hospital in Wrocław, Poland

psychotropic drugs changed only slightly (from $31 \%$ in 2005 to 39\% in 2015) (Figures 6a and 6b), but the mortality rate decreased significantly over the analyzed period (from 40\% in 2005 to 29\% in 2015) (Figures 6c and 6d). Nowadays the increasing numbers of poisonings caused by narcotics and hallucinogenic substances pose a significant problem. The number of hospitalizations due to this type of intoxication increased 19-fold over the years of observation, from 15 patients at the start to 288 patients at the end of 2015 (Figure 7). In this group, new psychoactive substances (NPS), colloquially known as "dopes," cause an increasing number of poisonings.

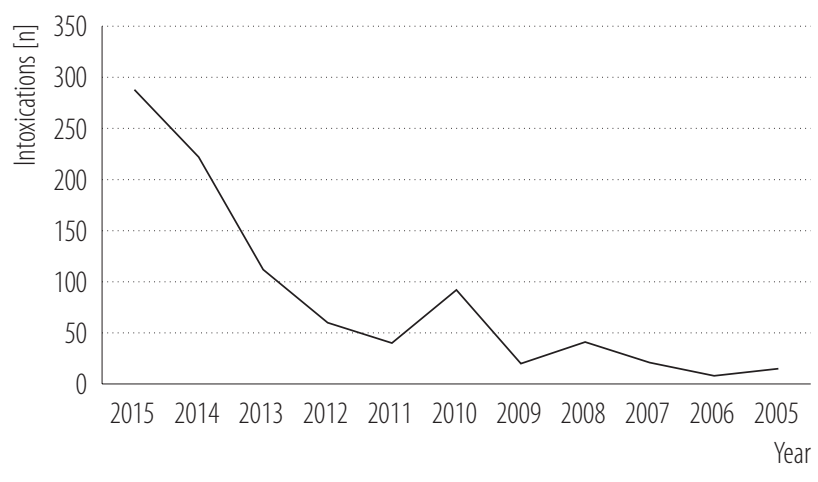

Figure 7. Intoxications caused by narcotics and hallucinogenic substances among the patients hospitalized in the Department of Toxicology and Internal Diseases of the T. Marciniak Lower Silesian Specialist Hospital in Wrocław, Poland, in 2005-2015 

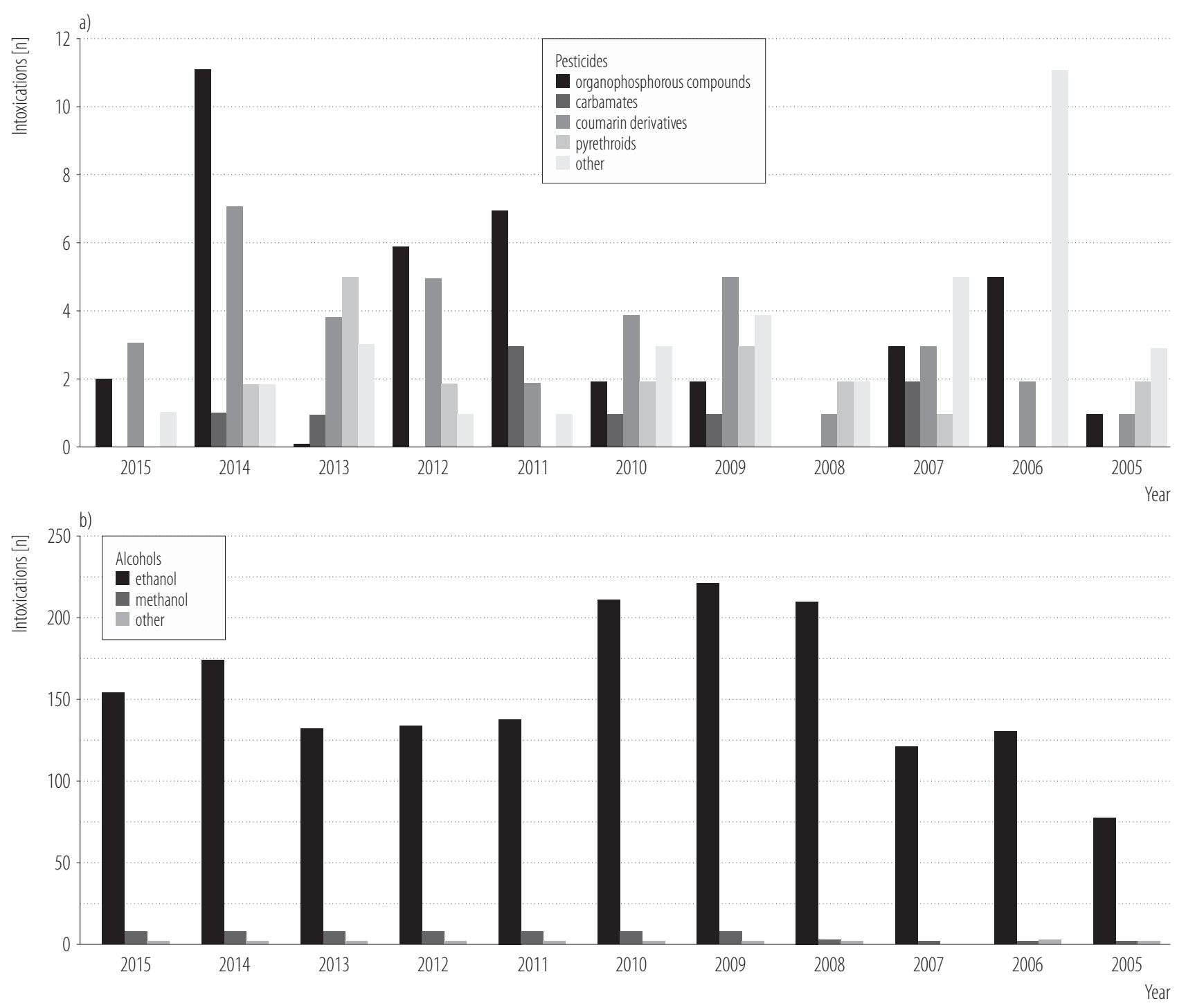

Figure 8. Intoxications caused by various a) pesticides and b) alcohols among the patients hospitalized in the Department of Toxicology and Internal Diseases of the T. Marciniak Lower Silesian Specialist Hospital in Wrocław, Poland, in 2005-2015

Figures $8 \mathrm{a}$ and $8 \mathrm{~b}$ show the number of cases of intoxication caused by various pesticides and alcohol, respectively, over the entire observation period. The total number of pesticide poisonings was relatively small (140 cases $-1.9 \%$ ). The poisonings were caused mainly by organophosphorus compounds $(28 \%)$ or coumarin derivatives $(26 \%)$, while the lowest number was caused by pyrethroids (14\%). The smallest group was made up of carbamate poisonings - only $6 \%$ (Figure $8 \mathrm{a}$ ). The number of ethanol poisonings increased from $8 \%$ in 2005 to $14 \%$ in 2015. Methanol poisonings were much less frequent - a few cases per year (Figure 8b). Some cases of intoxication, due to their cyclical incidence, may be classified as seasonal. The numbers of carbon monoxide or mushroom poisonings, in their appropriate quarters, are provided in Figures 9a and 9b, respectively. Carbon monoxide intoxication was especially frequent in the first and fourth quarters, while mushroom poisoning was the most frequent in the third and fourth quarters (Figures $9 \mathrm{a}$ and $9 \mathrm{~b}$ ). 

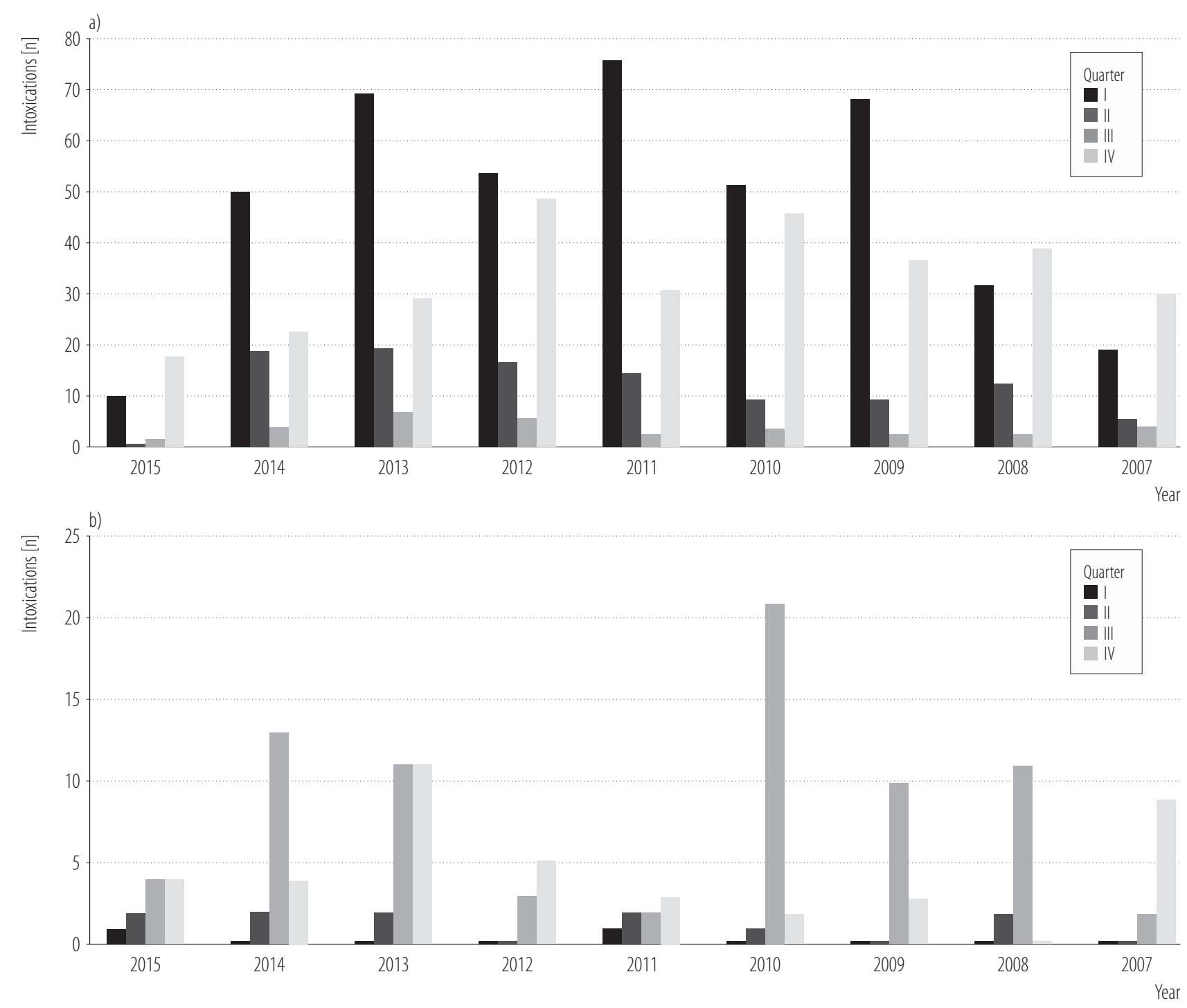

Figure 9. Quarterly a) carbon monoxide and b) fungal poisonings among the patients hospitalized in the Department of Toxicology and Internal Diseases of the T. Marciniak Lower Silesian Specialist Hospital in Wrocław, Poland, in 2005-2015

\section{DISCUSSION}

The total number of acute unintentional poisonings throughout the world ranges between 2-3 million cases annually, of which 1 million are severe poisonings resulting in 20000 deaths annually, while the estimated annual number of intentional poisonings is about 2 million, including 200000 suicides (WHO data) [11,12]. In this retrospective study, a tendency towards a gradual increase in the number of poisonings, especially among men, was shown over the 10-year observation period.

As regards mortality, a somewhat opposing tendency was noted, mainly among women. The most important genderrelated differences relate to the compounds metabolized by enzymes that are under the control of sex hormones. Generally, it is accepted as a toxicological rule that women are more susceptible than men to poisoning by many xenobiotics, especially psychotropic drugs and pesticides [13,14]. On the other 
hand, statistical data indicate that the standardized mortality rates are higher for men than for women for almost all major causes of death in the European Union (EU) $[15,16]$. Sex differences in the gene expression of transporters are the key causes of differences in sex-dependent pharmacokinetics, which may contribute to individual differences in many drug efficacies and toxicities [17]. During this retrospective observation study, there was a significant increase in the number of intoxicated patients in all age groups admitted to hospital, especially in the youngest group (15-30 years old). This increase in poisonings was probably due to the increased consumption of a new group of compounds, the so called "legal-highs," especially by young people. The literature data show that the number of young adults who had tried these substances grew from 5\% to 8\% between 2011 and 2014, whether bought independently or obtained from friends. The use of new psychoactive substances has become a permanent feature of drug poisoning in Poland, as well as generally in the UE, especially among young people. The creation of a legal solution that could help to minimize the poisoning risks associated with these new substances in an effective and rational way should be prioritized [18].

Regardless of the increase in the number of poisonings among young people, the highest mortality rate in this study group, during almost the entire time of observation, was evident among elder patients. Polypharmacy and intensification of adverse drug reactions are characteristic of this group. Age is not an independent risk factor for ADR, but age-dependent factors, such as changes in pharmacokinetics and pharmacodynamics, and polymedication, seem to be responsible for the risk of developing ADR and greater mortality in the elderly $[6,19]$. The research conducted by Hepner et al. [20] showed that in a Nuremberg hospital approximately $40 \%$ of the poisonings after drug administration occurred in the elderly. These included both accidental intoxication and suicide attempts, acute overdoses and chronic therapeutic poisoning, as well as ADR. Although both the morbidity and mortality of acute poisoning are increased in geriatric patients, the actual number of them represents a small percentage. While it is possible that young people are more likely to be victims of targeted poisoning, the cumulative side effects in older people may well be due to polypharmacy [21]. It is indicated that each category of toxic agents (drugs, ethanol, plants, etc.) has its own risk profile for elderly people [6].

As was revealed by the authors, the majority of the subjects enrolled in their study (58.2\%) had attempted suicide. Such cases of poisoning were significantly prevalent in the whole multi-annual observation study. According to WHO data (2015), Poland occupies the 15th position on the list of suicide rates by country. The age-standardized suicide rate (per 100000 inhabitants) in Poland showed a general change over time (2005 and 2015) of about 0.7 (in males 1.6 and in females 0.1) [22]. In the last 2 years of observation (2014-2015), the authors showed a significant increase in the number of cases treated due to drug overdoses, but not suicide. The widespread availability and the increasing use of OTC drugs might have had a significant impact on that [23]. Awareness of the risks among patients and pharmacists is of great importance [24]. In this study, drugs were the main cause of poisonings $(60.4 \%)$ for all the patients treated in the Department of Internal Medicine and Toxicology. However, single drug-caused intoxication was observed 2.8 times more often than mixed drug poisonings. The other most common causes were alcohol $(14.73 \%)$, gases $(10.7 \%)$, narcotic and hallucinogenic substances $(7.5 \%)$, mushrooms $(1.7 \%)$, organic substances $(1.2 \%)$ or pesticides $(1.2 \%)$ and glycols $(1.1 \%)$.

Poisonings are mainly due to the use of psychotropic drugs, and nowadays increasingly the use of NSAIDs and analgesics. The overdose of these drugs, as various statistics show [25], is becoming an important issue. An additional goal of this study was to show how the analyzed numerical data changed over the period of observation. In this retrospective study, the most frequently involved drugs were sedative, hypnotic and antiepileptic drugs (56\% in 2005). 
An important and optimistic fact is that in 2015 intoxication by these drugs, as observed in the study population, decreased to $37 \%$. The literature data indicate neuroleptics and antidepressants as the main causes of the severity of poisonings, due to their chemical character and pharmacokinetics [26]. Recent years have seen a decrease in the frequency of poisonings with tricyclic antidepressants, and a significant increase in drug poisonings classified as "other," which include, for example, the new generation of antidepressants: serotonin norepinephrine reuptake inhibitor, selective serotonin reuptake inhibitor and atypical antidepressants, such as trazodone and mianserin [27]. Nonetheless, attention should be paid to poisonings with analgetics, antipyretic and antinflammatory drugs, because of their significant increase during the period of our observation, up to $14 \%$ in 2015 . This increase might have resulted from the sale of these drugs outside pharmacies, which is currently a very important issue in Poland, requiring a comprehensive legal solution to be introduced. This retrospective study, conducted in only 1 toxicological department, makes it possible to clarify a tendency concerning the dramatic increase in OTC drug poisonings prevalent in Poland, especially involving drugs such as paracetamol, ibuprofen and acetylsalicylic acid compounds.

Although narcotic and hallucinogenic substances were only the fourth cause of intoxication in this study, they constitute a current, and still growing, global problem. In this retrospective study, the authors observed a significant increase in poisonings with this group of compounds. In 2005, hallucinogens and narcotics accounted for only 10-15 cases, whereas in 2015 there were almost 300 such patients, and this is consistent with the global tendency. In the past, most drug abuse and addiction cases involved amphetamines, cannabis, cocaine and heroin, whereas nowadays NPS are an increasing problem. The European Monitoring Centre for Drugs and Drug Addiction notes that $>450$ NPS have been introduced for illegal use since 2004 [28,29].
The analysis conducted by the authors revealed that the second reason for treatment in the Department of Toxicology was alcohol. Acute alcohol intoxication remains a particular challenge for clinical and non-clinical emergency facilities [30]. The age of patients with alcohol poisoning is still decreasing [31,32]. In this study, ethanol poisoning did not show a clear trend. The number of cases treated in hospital increased from 70 to 220 a year. Methanol poisoning occurred in only a few patients, and in recent years the amount of alcohol poisonings has increased slightly. Gases constituted the third cause of poisoning, with carbon monoxide as the most potentially fatal form. Accidentrelated intoxication is common in winter, connected with the use of gas heating, but throughout the year there are cases of suicide attempts involving carbon monoxide [33]. In Poland the number of carbon monoxide poisonings is on a downward trend, which may be related to a shift away from coal and gas furnaces, as a result of legislative action in our country and the UE.

A similar seasonal trend was observed in relation to mushroom and pesticide intoxication. Around 500-1000 cases of mushroom poisoning are diagnosed annually in Poland, of which about $70 \%$ are experienced by adults. One of the most dangerous mushrooms in our climate is undoubtedly Amanita phalloides. Statistical data show that the mortality rate for people intoxicated with this kind of mushrooms is about $30 \%$, with mortality among adults constituting $20 \%$, while in children about $50 \%$ [34].

The number of pesticide poisonings in the analyzed data was relatively small, probably due to the fact that Wrockaw is an industrialized region. In agricultural areas, pesticide poisoning is certainly much more noticeable, especially in summer [3]. Morbidity and mortality due to organophosphorus poisoning are directly proportional to age, the severity of poisoning and the duration of mechanical ventilation, as well as inversely proportional to the serum cholinesterase level. However, interestingly, most of the observed poisonings were related to suicide $[35,36]$. 


\section{CONCLUSIONS}

Poisoning statistics change dynamically. The long-term observations made by the authors outlined these changes more precisely. Despite the lack of a uniform trend in poisonings, over the 10 -year observation period the number of hospitalized patients increased, especially among men. The mortality rate decreased slightly, especially among women, with the mortality rate remaining the highest among men. Moreover, intoxication was most likely to occur among young people (aged 15-30), but the highest mortality was evident among elder patients, indicating the importance of the intoxication problem regardless of age. Still, the majority of the subjects had attempted suicide and the most common cause of poisoning was drugs.

The most frequently used drugs were sedatives, hypnotics and antiepileptics, but the group of NSAIDs, especially OTC drugs, caused the highest mortality, which points to the problems of non-pharmacy sales [37]. According to the authors, the epidemiological profile data from their investigation of poisonings in Lower Silesia could be very useful in the development of preventive programs connected with both intentional and accidental poisonings.

\section{ACKNOWLEDGMENTS}

The authors would like to thank Dr. Krystyna Kochmann Head of the Department of Toxicology and Internal Diseases of the T. Marciniak Lower Silesian Specialist Hospital in Wrocław, as well as the Director of the hospital, for sharing the descriptive data presented in this article. Moreover, the authors are grateful to Marta Leońska for technical preparation of figures.

\section{REFERENCES}

1. Cierniak-Piotrowska M, Marciniak G, Stańczak J. [Statistics of deaths and mortality due to cardiovascular diseases]. In: Strzelecki Z, Szymborski J, editors. [Morbidity and mortality of cardiovascular diseases and the demographic situation in Poland]. Warszawa: Rządowa Rada Ludnościowa; 2015. p. 46-7. Polish.
2. World Health Organization [Internet]. Geneva: The Organization; 2017 [cited 2017 Aug 12]. Management of substance abuse. Acute intoxication. Available from: http://www.who. int/substance_abuse/terminology/acute_intox/en/.

3. Sulaj Z, Prifti E, Demiraj A, Strakosha A. Early Clinical Outcome of Acute Poisoning Cases Treated in Intensive Care Unit. Med Arch. 2015;69(6):400-4, https://doi.org/10.5455/ medarh.2015.69.400-404.

4. Hydzik P, Krośniak M, Francik R, Gomółka E, Ebru ED, Zagrodzki P. [Serum antioxidant parameters in patients poisoned by different xenobiotics]. Acta Pol Pharm. 2016; 73:337-44. Polish.

5. Doak MW, Nixon AC, Lupton DJ, Waring WS. Self-poisoning inolderadults:patternsofdrugingestionandclinicaloutcomes. Age Ageing. 2009;38(4):407-11, https://doi.org/10.1093/age ing/afp046.

6. Mühlberg W, Becher K, Heppner HJ, Wicklein S, Sieber C. Acute poisoning in old and very old patients: a longitudinal retrospective study of 5883 patients in a toxicological intensive care unit. Z Gerontol Geriatr. 2005;38(3):182-9, https:// doi.org/10.1007/s00391-005-0309-7.

7. Routledge PA, O’Mahony MS, Woodhouse KW. Adverse drug reactions in elderly patients. Br J Clin Pharmacol. 2004;57(3): 121-6, https://doi.org/10.1046/j.1365-2125.2003.01875.x.

8. Heyerdahl F, Bjornas M, Hovda KE, Skog K, Opdahl A, Wium C, et al. Acute poisonings treated in hospitals in Oslo: a one-year prospective study (II): clinical outcome. Clin Toxicol. 2008;46(1):42-9, https://doi. org/10.1080/15563650701210048.

9. Wesołowski A, Woźniak A, Sawicka E. [Out of pharmacy sale of OTC pharmaceuticals-opinions of patients of primary health on selected issue]. Farm Pol. 2015;71:665-9. Polish.

10. [Pharmaceutical Law Act of 6 September 2001]. J Laws. 2008, No. 45, item 271, art. 37al. Polish.

11. Banerjee I, Tripathi S, Roy AS. Clinico-epidemiological characteristics of patients presenting with organophosphorus poisoning. N Am J Med Sci. 2012;4(3):147-50, https:// doi.org/10.4103/1947-2714.93884. 
12. Mariam ETG, Gelaw BK. Global epidemiology of acute poisoning with an emphasis to Ethiopia: systematic review. Int J Pharm Sci Scient Res. 2016;2(4):161-71.

13. Puchalska H. [Factors affecting the toxicity of chemical substances]. Bezp Pr Nauk Prakt. 1999;4:12-4. Polish.

14. Sakuma T, Kawasaki Y, Jarukamjorn K, Nemoto N. Sex differences of drug metabolizing enzyme: female predominant expression of human and mouse cytochrome P450 3A isoforms. J Health Sci. 2009;55(3):325-37, https://doi. org/10.1248/jhs.55.325.

15. Emanuele N, Emanuele MA. Alcohol alters critical hormonal balance. Alcohol Health Res World. 1997;21(1):53-64.

16. Eurostat Statistics Explained [Internet]. 2017 [cited 2017 Jul 16]. Causes of death statistics. Available from: http:// ec.europa.eu/eurostat/statistics-explained/index.php/ Causes_of_death_statistics/pl.

17. Joseph S, Nicolson TJ, Hammons G, Word B, GreenKnox B, Lyn-Cook B. Expression of drug transporters in human kidney: impact of sex, age, and ethnicity. Biol Sex Differ. 2015;6:4, https://doi.org/10.1186/s13293-015-0020-3.

18. European Commission, Directorate-General for Communication. Flash Eurobarometer 401, Young People and Drugs [Internet]. Brussels: The Commission; 2014 [cited 2017 Aug 12]. Available from: http://ec.europa.eu/commfrontoffice/publicopinion/flash/fl_401_en.pdf.

19. Ciorciaro C, Hartmann K, Kuhn M. [Differences in the relative incidence of adverse drug reactions in relation to age? An evaluation of the spontaneous reporting system of SANZ (Swiss Drug Monitoring Center)]. Schweiz Med Wochenschr. 1998;128:254-8. German.

20. Heppner HJ, Christ M, Gosch M, Mühlberg W, Bahrmann P, Bertsch T, et al. Polypharmacy in the elderly from the clinical toxicologist perspective. Z Gerontol Geriatr. 2012;45(6):473-8, https://doi.org/10.1007/s00391-012-0383-6.

21. Routledge PA, O’Mahony MS, Woodhouse KW. Adverse drug reactions in elderly patients. Br J Clin Pharmacol. 2004;57(2):121-6, https://doi.org/10.1046/j.1365-2125.2003. 01875.x.
22. World Health Organization [Internet]. Geneva: The Organization; 2017 [cited 2017 Aug 12]. Global Health Observatory data respiratory. Suicide rate estimates, age-standardized estimates by country. Available from: http://apps.who.int/gho/ data/node.main.MHSUICIDEASDR?lang=en.

23. Zaprutko T, Koligat D, Michalak M, Wieczorek M, Józiak M, Ratajczak M, et al. Misuse of OTC drugs in Poland. Health Policy. 2016;120(8):875-81, https://doi.org/10.1016/ j.healthpol.2016.06.008.

24. Piecuch A, Makarewicz-Wujec M, Kozłowska-Wojciechowska M. Improving the provision of OTC medication information in community pharmacies in Poland. Int J Clin Pharm. 2017;39(10):70-7, https://doi.org/10.1007/s11096016-0397-z.

25. Lessenger JE, Feinberg SD. Abuse of prescription and over-the-counter medications. J Am Board Fam Med. 2008;21(1):45-54, https://doi.org/10.3122/jabfm.2008.01.070 071.

26. Luer MS, Penzak SR. Pharmacokinetic Properties. In: Jann MW, Penzak SR, Cohen LJ, editors. Applied Clinical harmacokinetics and Pharmacodynamics of Psychopharmacological Agents. Cham, Heidelberg, New York, Dordrecht, London: Springer International Publishing; 2016, p. 3-27, https://doi.org/10.1007/978-3-319-27883-4_1.

27. Jaszczyszyn A, Gąsiorowski K, Świątek P, Malinka W, Cieślik-Boczula K, Petrus J, et al. Chemical structure of phenothiazines and their biological activity. Pharmacol Rep. 2012;64(1):16-23, https://doi.org/10.1016/S1734-1140 (12)70726-0.

28. Huestis MA, Tyndale RF. Designer Drugs 2.0. Clin Pharmacol Ther. 2017;101(2):152-7, https://doi.org/10.1002/cpt.575.

29. Pourmand A, Mazer-Amirshahi M, Chistov S, Li A, Park M. Designer drugs: Review and implications for emergency management. Hum Exp Toxicol. 2018;37(1):94-101, https:// doi.org/10.1177/0960327117698542.

30. Gruettner J, Walter T, Lang S, Reichert M, Haas S. Risk assessment in patients with acute alcohol intoxication. In Vivo. 2015;29(1):123-7. 
31. Chen F, Wen J, Wang X, Lin QM, Lin CJ. Epidemiology and characteristics of acute poisoning treated at an emergency center. World J Emerg Med. 2010;1(2):154-6.

32. Hendler RA, Ramchandani VA, Gilman J, Hommer DW. Stimulant and sedative effects of alcohol. Curr Top Behav Neurosci. 2013;13:489-509, https://doi.org/10.1007/7854_2011_135.

33. Yurtseven S, Arslan A, Eryigit U, Gunaydin M, Tatli O, Ozsahin F, et al. Analysis of patients presenting to the emergency department with carbon monoxide intoxication. Turk J Emerg Med. 2015;15(4):159-62, https://doi.org/10.1016/ j.tjem.2015.05.001.

34. Ferenc T, Łukasiewicz B, Ciećwierz J, Kowalczyk E. [Poisonings with Amanita Phalloides]. Med Pr. 2009;60(5):415-26. Polish.

35. Patil G, Murthy N, Nikhil M. Contributing Factors for Morbidity and Mortality in Patients with Organophosphate
Poisoning on Mechanical Ventilation: A Retrospective Study in a Teaching Hospital. J Clin Diagn Res. 2016;10(12): UC18-20, https://doi.org/10.7860/JCDR/2016/22116.9038.

36. Krakowiak A, Piekarska-Wijatkowska A, Kobza-Sindlewska K, Rogaczewska A, Politański P, Hydzik P, et al. Poisoning deaths in Poland: Types and frequencies reported in Łódź, Kraków, Sosnowiec, Gdańsk, Wrocław and Poznań during 2009-2013. Int J Occup Med Environ Health. 2017;30(6):897-908, https://doi.org/10.13075/ijomeh.1896. 01063.

37. Morthorst BR, Erlangsen A, Nordentoft M, Hawton K, Groth Hoegberg LC, Dalhoff KP. Availability of Paracetamol Sold Over-the-Counter in Europe: A Descriptive CrossSectional International Survey of Pack Size Restriction. Basic Clin Pharmacol Toxicol. 2018;122(6):643-9, https://doi. org/10.1111/bcpt.12959.

This work is available in Open Access model and licensed under a Creative Commons Attribution-NonCommercial 3.0 Poland License - http://creativecommons.org/ licenses/by-nc/3.0/pl/deed.en. 